\title{
Analysis on Psychological Factors Impacting Insider Trading
}

\begin{abstract}
Zijing Yao
University of Nebraska-Lincoln, Lincoln, NE, 68504, USA

*Corresponding author.Email: Zyao2@unl.edu

ABSTRACT

Insider trading is one of the most representative commercial deception. Although insider trading is unethical and illegal, it still happens frequently in the U.S., even around the world. There are many studies focusing on the relationship between insider trading and moral problems, but there is lack of evaluation and analysis about the psychological and sociological reasons that cause the insider trading. This research devoted to evaluating the relationship between psychological factors and insider trading by analyzing the real cases, including Samuel Waksal Case, Yoshiaki Murakami Case, and Richard Burr Case. The propose for this study is to find the reason why people like to do insider trading under some psychological and sociological theories. The author focuses on using operant conditioning theory, conformity theory and some ethical theories to discuss the influencing factors of insider trading.
\end{abstract}

Keywords: Insider trading, Operant conditioning theory, Conformity, Ethical

\section{INTRODUCTION}

Insider trading is one of the most representative commercial deception. According to Investor (n.d.) [5], illegal insider trading usually refers to buying and selling securities based on non-public information. Any gain from buying or selling the security that based on this kind of activity is illegal and unethical. Although all people know this kind of activity is illegal and unethical, it is still repeatedly taking place day by day. For now, people only focus on the relationship between insider trading and moral issue but overlook the deep reasons that cause the activity to happen. This paper tried to explore more about the psychological and sociological reasons of why people intend to take risk on doing this kind of trading. Within this paper, the author would explore and try to explain the factor that cause the insider trading through operant conditioning theory, conformity theory and some ethical theories. From the psychological point of view, since punishment always comes much later than the reinforcement, the effectiveness of punishment has a diminishing effect. Due to the complexity of insider trading judgement, some of the lawsuits of insider trading need a long period, and some people would not be punished finally. When people find out that those people have not be punished, they are more willing to do insider trading. In addition, as the profit is huge sometimes, people would like to take the risk although they know this activity is wrong and unethical. From the sociological point of view, sometimes when people are in high social status, they have more chances to touch people with strong power, and they may have more chances to avoid the potential punishment. For the final point, since there is inconsistent ethical standard for all the people, personal ethical standard plays an important role on insider trading. The main purpose of this paper is to analyze these psychological and social reasons of insider trading, and consider how to make changes to reduce insider trading by understanding these reasons.

\section{RESEARCH METHODOLOGY}

The propose of doing this research is to explore more about the reason why insider trading happen through some psychological and sociological theories. The theories which included in this research were using operator conditioning theory, conformity theory and some ethical theory related to personal ethic standard. By analyzing the real cases, this paper is devoted to analyzing the psychological reasons behind insider trading.

\subsection{Instrumentation}

The data of the research was collected from the past cases that already happened and the author analyzed 
potential reasons from the psychological and sociological perspectives. The three main cases that used in this study were Samuel Waksal case, Yoshiaki Murakami case, and Richard Burr case. This research would explain those cases in detail to find out the psychology and sociology reason cause the insider trading.

\subsection{Assumptions}

\subsubsection{Effectiveness of legal punishment playing important role in insider trading}

According to operant conditioning, when punishment and reinforcement coexist, the effectiveness of punishment will be weaken or even become extinct. When punishment cannot immediately follow insider trading, and the benefits brought by insider trading have strong appeal. The benefit of insider trading will be a strong reinforcer, which will lead to the effectiveness of punishment being reduced. If punishment is more deterrent than the benefits brought by insider trading, the probability of insider trading will decrease.

\subsubsection{Conformity}

If people have had insider trading and gained huge benefits without being punished by law, people will tend to do the same. In many cases, people will follow the behavior of others. For example, the most famous conformity experiment is the ASCH Conformity Experiments (Asch, 1951), that is, participants change their correct answers because they are inconsistent with others' answers. In insider trading, when people find that other people have not been punished for this kind of behavior but obtain huge benefits, people will follow it. According to Bernheim [2], people may be affected by other people who have close relationship with them to a great extent. People are willing to conform because they think even little departures may hurt their social status.

\subsubsection{Attraction of high returns}

High-yield insider trading has strong appeal even though it also has high risks. People think that they will not be monitored and punished by relevant departments. There is no way for relevant departments to effectively monitor everyone and punish them effectively in time. People will be attracted by benefits so that they would conduct inappropriate or even illegal behaviors. The profit from insider trading is usually of a large amount, so people may not be able to resist it.

\subsubsection{The role of social networks}

People who have the ability to get inside information are usually powerful people, and their social networks help them reduce the risk of insider trading so that they are more likely involved in insider trading. When the social networks around people could help them get huge benefits and evade responsibilities, people are more likely to make high-risk behaviors. This is why insider trading only appears in the top class of society.

\subsubsection{The balance between guilt and social responsibility}

People who have lower personal ethic standard are easier to be involved in insider trading. People's moral standards will influence people's decisions. As a result, some people will commit illegal acts because of profit, while others will not. If people are found to be involved in insider trading, without realizing that they have made mistakes, but thinking about why they were found. Such people are more likely to participate in insider trading than those who feel guilty.

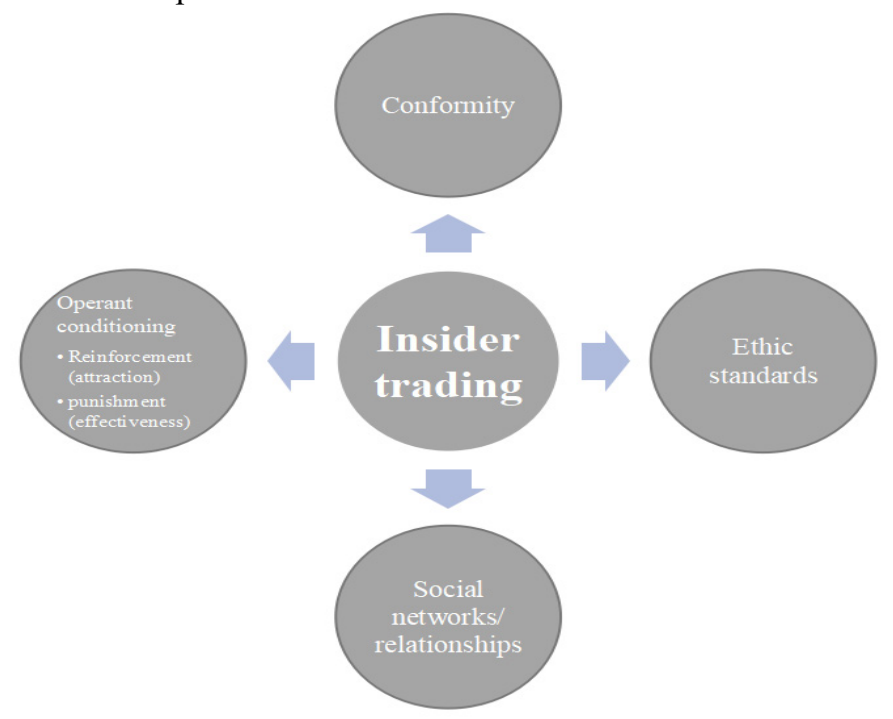

Figure 1 Main hypothesis in this study 


\section{ANALYSIS OF CASES}

\subsection{Samuel Waksal Case}

According to SEC [7], Samuel Waksal was involved in one insider trading that related to ImClone stock. In December 2001, Samuel Waksal, as the top management of ImClone, received one message from the US Food and Drug Administration to reject ImClone's new medicine: Erbitux. Once he knew this non-public information, he talked to his family member and told them to sell the ImClone's stock to avoid the losses from the stock price cutoff. All of those actions are based on the non-public information, so Waksal violated the law and need to pay for high violation fine for his activity.

From this case, since the stock amount Waksal and his family is so huge (more than $\$ 10$ million), the reward from this insider trading is considerable. Also, since Waksal is the top management of ImClone, he could get the information much earlier than other people from the government, he has the ability to do the insider trading. According to Skinner [8], operant conditioning means people's behavior "controlled by its consequence". Under this situation, the reward is high, and the potential punishment is low, or he thought he has the chance to avoid the punishment since he is one powerful and rich people with a high social status. The consequence for him is high reward come with low risk. In addition, since he although told the information to his family member, according to Germar, Albrecht, Voss \& Mojzisch [3], people's personal opinion could be strongly influenced by other people who near them or do the similar thing like they do because of the conformity effect. Under the conformity effect people are more likely to follow the "common sense" and do what other people may do in the same situation. Family member could be one important role that changed his mind and helped him to make the decision about doing insider trading since they have close relationship with Waksal. Since he has the strong motive and enough ability to do the insider trading, combined with his own low personal ethic standard, he finally did the insider trading and shared his information with his family member.

\subsection{Yoshiaki Murakami Case}

According to Reuters [6], Japanese financier Yoshiaki Murakami was jailed in 2007 after he was founded that he involved in one insider trading. He also received one 1.2 billion yen (around US $\$ 10$ million) fine related to this insider trading. The bureaucrat showed that Murakami bought the Nippon Broadcasting System stock based on some non-public information that he has and get the profit from this purchase transaction. As the final result, Yoshiaki Murakami has to go jail for two years and pay for the most expensive fine related to insider trading in Japan's history.

Yoshiaki Murakami case is similar as Samuel Waksal case. They are both in high social status, have the ability to get some unique information that nonpublished to public, and have more social relations to reduce the possibility to be punished by the government. Since they have the strong motive, and have lower possibility to be punished, the effectiveness of legal punishment is low for them, and the reward for them to do the insider trading is high, so they like to do the insider trading to gain more profit. Even before Murakami was found guilty, he was proud of what he done, it shows that he really did not think what he has done was wrong.

\subsection{Richard Burr Case}

Unlike Samuel Waksal and Yoshiaki Murakami was punished by government, Richard Burr just was investigated by FBI, but not be punished as one insider trader. According to Burns \& Millhiser [1], Richard Burr was considered that involved in the insider trading cases related to COVID-19. Before the pandemic of COVID-19 in the United State, Richard Burr received many non-public information that related to the potential influence after the COVID-19. During that period, he and his wife sold 33 stocks which include hotel, restaurant, and transportation industry. After they sold those stocks, all of those industries are strong negatively influenced by COVID-19.

In this case, since Richard Burr was one senior government official, he could receive much more information related to the impact of COVID-19. Since he was one senior government official who has a bad relationship with President Trump, it was difficult to judge if he really does the insider trading or this accuse has any political factor. Although Burr really do the transaction, it is difficult to judge if this transaction involved insider trading. Burr's case is significantly different from other cases. Burr's case occurred during the outbreak, and the spread of pneumonia in COVID19 is well known. Because it is difficult to judge whether he made "insider trading" based on non-public information. However, since they really get the profit from the selling transaction and Burr has the chance to receive more non-public information, the motivation and ability to do insider trading was valid.

\section{DISCUSSION}

By analyzing three different cases, the author finds that the people involved in insider trading all have a high social status or job position, which means that their social networks are different from those of ordinary people. They are more able to get access to non-public information and participate in insider trading. Besides, 
when they participate in insider trading, their social networks would help them obtain non-public information or reduce their punishment. Furthermore, there is no doubt about the high returns brought by insider trading. Therefore, the author predicts that people will be tempted by high returns and participate in insider trading. Compared with the temptation of high return, legal punishment is unstable. Through analysis, the author finds that when people are faced with reinforcer (high return) and punisher (possible legal consequences), the effectiveness of punishment is greatly reduced. It is also because the punishment cannot be carried out immediately after insider trading, which leads to its lower effectiveness and people who involved in insider trading pay more attention to high returns rather than the risks. What is more, although the insider trading is discovered and reported, it does not mean all insider trading behaviors have been found, which makes people misunderstand that there is an outstanding possibility of escaping punishment. As it is difficult for the government or relevant departments to effectively monitor insider trading, it is easy for people to be tempted to commit illegal acts just because insider trading can bring large profits more easily. Further, people's desire for insider trading is stronger, and the failure of timely punishment reduces people's fear of negative consequences. Due to the high reward and low possibility to be punished, people will trend to accept the risk and conduct the insider trading to gain the profit.

Moreover, sometimes it is difficult for the government to judge whether a person is involved in insider trading. For example, Richard Burr Case showed that the government did not have enough evidence to prove that he made "insider trading" because he got non-public information or just based on the excellent business forecasting ability. In addition to the temptation of high interests and the punishment that is difficult to appear in time, punishment's effectiveness will be weakened in that people can use their social relations to reduce or even escape punishment. As the most common participants in insider trading, people in high social class can use their social ties to reduce the penalty.

For the analysis of conformity, the author has no substantial evidence to show the following behaviors in these cases. However, it is found that insider trading participants are generally familiar with each other, so the conformity phenomenon is possible. If people notice that others are not being punished accordingly, they will show conformity, which will lead to an increase in insider trading. After observing the real cases in which the success of other people around them who benefited from insider trading, people will believe that punishment is of low probability. Thus, the author thinks that due to the untimely punishment and the temptation of high return, the possibility of conformity is likely to happen. This is also an aspect that needs more attention in future research. In addition to the above elements, the author also finds that the standard played a critical role in illegal activities. It can restrain people's unreasonable behavior. However, not everyone feels guilty after the unlawful act is discovered. Just like Yoshiaki Murakami, some people may not see insider trading as a serious issue. When low ethical standard combines with high motivation, insider trading will trend to happen. Therefore, personal moral standard is an important influencing factor.

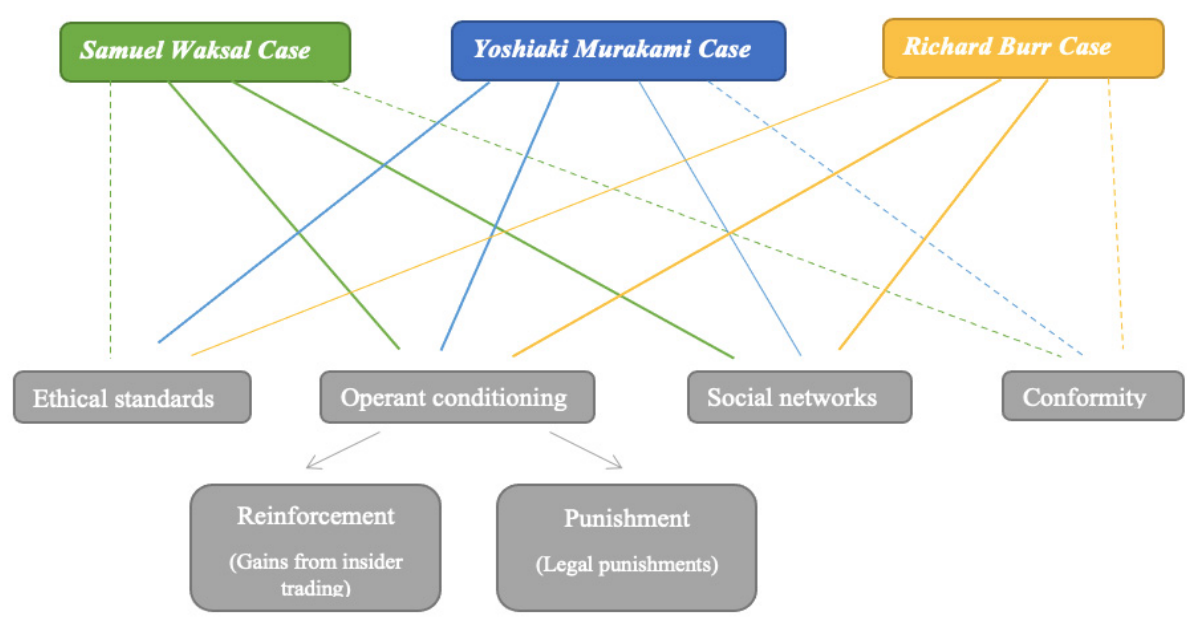

Figure 2 Correlation analysis results of three cases

*Thick lines represent great association, thin lines represent association, and dashed lines represent little association.

Generally speaking, by analyzing three cases, the author finds that the assumptions basically accord with the analysis. The delay and instability of punishment will reduce its effectiveness. At the same time, insider trading with high returns has a strong temptation. Besides, the phenomenon of conformity exists if 
punishment is often not effectively implemented. In this case, the deterrent power of punishment is reduced, making people more vulnerable to temptation. There is no doubt that the vast profits brought by insider trading are attractive. The difference is that whether people can refuse this temptation is influenced by social relations, personal moral standards, and the effectiveness of punishment. Social networks play a significant role in insider trading. It is a channel for people to provide nonpublic information and intervene in the degree of punishment after insider trading is revealed. Therefore, this is why people living in the working class, high social class, or top social class usually participate in insider trading compared with the middle class.

Through the analysis in this paper, the author thinks it is necessary to increase the deterrent and enforcement power of punishment. The author suggests that the relevant regulatory authorities should monitor companies' behavior and people with a high social status more effectively. It is undeniable that it is challenging for the government to monitor every company or person at present effectively, so this is the most difficult and most needed problem to overcome. Besides, in current society, society's development is mainly controlled by people with high social status, which makes it more difficult for politics and law to monitor their inappropriate behaviors. The market supervision department should also implement stricter management of non-public information and minimize the possibility that someone will risk disclosing information to outsiders. In future research, researchers should try to find out how to improve monitoring ability and reduce monitoring costs.

\section{CONCLUSION}

Admittedly, the results of this study are only based on the analysis of these three cases. Because the analysis samples are limited and quantitative data are not used, the results may only apply to the most common insider trading cases, but not to some complex cases involving many factors. Because only a few real cases are analyzed, the experimental conclusion may not fully summarize all insider trading. Therefore, the generalizability of the research results is uncertain, which is also a problem that needs to be overcome in future analysis, meaning that how to ensure the generalization of these psychological factors. In future research, more detailed analysis is necessary.

Imagine if people have the same money, power, and celebrity, would they choose to do the same thing? Many times, people firmly believe that they will not do the same behavior, but everything is not what people think when people have power. There are many experiments in psychology that can prove that rights change people. For example, the Stanford Prison Experiment [4], as the most classic experiment, fully embodies people's influence of rights and status. When ordinary college students have the privilege of prison management, they will slowly begin to abuse their power. Therefore, the psychological or sociological theory behind insider trading is worth studying and needs further study.

In a word, this paper analyzes the psychological factors behind insider trading mainly based on operant conditioning and conformity theories. However, this is only a superficial analysis. To make full use of psychology to think about how to reduce insider trading, more detailed experimental research and analysis are required.

\section{AUTHORS' CONTRIBUTIONS}

The author completed this paper through reading references and making analysis by herself.

\section{ACKNOWLEDGMENTS}

I would like to thank my instructor Andrew Wicks for his excellent course on business ethics and his consistent support and guidance during the project operation. In addition, I would like to thank other members of the undergraduate research team for their help and cooperative efforts in the process of revising the thesis. I would also like to thank my friends for their suggestions and help in this research.

\section{REFERENCES}

[1] K. Burns \& I. Millhiser, Sen. Richard Burr and the coronavirus insider trading scandal, explained. Vox. 2020, May 14, https://www.vox.com/policy-andpolitics/2020/5/14/21258560/senator-richard-burrcoronavirus-insider-trading-scandal-explained.

[2] B. D. Bernheim, A Theory of Conformity. Journal of Political Economy. 1994, October 1, https://www.journals.uchicago.edu/doi/abs/10.1086 $/ 261957$.

[3] M. Germar, T. Albrecht, A. Voss \& A. Mojzisch, Social conformity is due to biased stimulus processing: electrophysiological and diffusion analyses. 2016, April 28, https://academic.oup.com/scan/article/11/9/1449/2 223572 .

[4] C. Haney, W. C. Banks \& P. G. Zimbardo, A study of prisoners and guards in a simulated prison. Naval Research Review, 1973, 30, pp. 4-17.

Insider

Trading.

https://www.investor.gov/introduction-

investing/investing-basics/glossary/insider-trading. 
[6] Reuters, Japan Financier Murakami Jailed for Insider Trade. 2007, July 18, CNBC. https://www.cnbc.com/id/19837165.

[7] SEC Charges Former ImClone CEO Samuel Waksal With Illegal Insider Trading, 2002, June 12, https://www.sec.gov/news/press/2002-87.htm.

[8] B. F. Skinner, Two Types of Conditioned Reflex: A Reply to Konorski and Miller. The Journal of General Psychology, 1937, 16(1), pp. 272-279. https://doi.org/10.1080/00221309.1937.9917951 